\section{ANTES, DESDE Y PARA \\ EL EXILIO. HERENCIA DE ESTA ÉPOCA (1935/1962) DE ERNST BLOCH}

\author{
Miguel Salmerón Infante \\ Universidad Autónoma de Madrid \\ Departamento de Filosofía. Facultad de Filosofía y Letras \\ c/ Francisco Tomás y Valiente, 1. Campus de Cantoblanco. \\ 28049 Madrid \\ miguel.salmeron@uam.es
}

\section{BEFORE, FROM AND FOR THE EXILE. HERITAGE OF THESE TIMES (1935/1962): ERNST BLOCH}

\begin{abstract}
The first edition of Erbschaft dieser Zeit was published in Zurich in 1935, during Ernst Bloch's five-year period of emigration from Nazi-Germany in various European capitals before his final emigration to America for ten years in 1938. In this book Bloch made a courageous stand in defence of the artistic avant-garde against the dogmatic advocates of socialist realism. His particularly adversary was Georg Lukács. But of course one of the most fascinating aspects of the book is that is also reads as a contemporary observation of the rise of the Nazis. Erbschaft is undoubtedly the major work of Weimar Germany Exile.
\end{abstract}

KEY WORDS: Exile; heritage; dialectics; diversion; intoxication; objectivity; montage; novum; tendency-latency; expressionism; epic theatre.

Es dificil encontrar un texto más significativo sobre el exilio de la República de Weimar en particular y más lúcido sobre el exilio en general que Erbschaft dieser Zeit (1935), Herencia de esta época, de Ernst Bloch.

Bloch es uno de los pensadores occidentales especialmente marcados por el exilio. Experiencia que hubo de tener en tres ocasiones. La primera en 1917 cuando vivió en Suiza, la segunda a partir de 1933 en Viena, Praga y Estados Unidos, y la última desde 1961 en la República Federal de Alemania. En definitiva, Bloch huyó primero del imperialismo guillermino, luego del nacionalsocialismo y finalmente del socialismo real.

Quizás se antoje que Bloch se trata de un perdedor de la historia, cuya filosofía está periclitada. No creemos que sea así. Independientemente de la vigencia dudosa de alguna de sus tesis inscritas en el marxismo-leninismo, rechaza-
RESUMEN: La primera edición de Erbschaft dieser Zeit fue publicada en 1935 en Zurich, durante la emigración de Ernst Bloch de la Alemania nazi por un período de cinco años en el que residió en varias capitales europeas antes de su marcha definitiva a América en 1938, donde vivió diez años. En este libro Bloch hace una encorajinada defensa de la vanguardia artistica contra los abogados del realismo socialista. Su adversario especifico era Georg Lukács. Pero sin duda alguna uno de los aspectos más fascinantes de este libro es que puede leerse como una observación contemporánea de la ascensión al poder de los nazis. Erbschaft es indudablemente la obra clave del exilio de la Alemania de Weimar.

PALABRAS CLAVE: Exilio; herencia; dialéctica; distracción; embriaguez; objetividad; montaje; novum; tendencia-latencia; expresionismo; teatro épico.

mos abiertamente el desdén que éstas puedan generar en los supuestos ganadores. De Bloch hemos de ponderar ante todo el vigor para pensar su época. Igualmente merece siempre ser tenida en cuenta su oposición a un pretendido progresismo, que abocando en la máquina y en la funcionalidad, desprecia gran parte de los aspectos de la tradición cultural de occidente aprovechables para el avance y la liberación del hombre. Una muy valiosa oposición a ese progresismo oscurantista, empobrecedor y filisteo, que en nombre de la ilustración "en nada ha sabido salvar lo que de valioso hubiera en el movimiento ilustrado" (Ramos, 1999, 15).

Herencia es un texto originariamente publicado en la editorial Oprecht \& Helbling en 1935 en Zurich, es decir, data de su segundo exilio, sin duda el más comprometido y arriesgado ${ }^{1}$, pues había comenzado dos años antes, desde la Machtergreifung de Hitler en 1933. Un exilio que Bloch 
más que muchos otros se vio forzado a abrazar por su condición de judío y miembro del KPD, pero que también asumió motu proprio por tratarse de un individuo políticamente activo, pero sobre todo agudamente lúcido en sus diagnósticos y valoraciones de un statu quo concreto. Esto es muy importante resaltarlo Bloch fue un afectado y un perjudicado por el exilio, pero con su firme resistencia política al nazismo antes, durante y después de éste, nunca fue víctima, como por ejemplo si lo fuera Walter Benjamin. Herencia se trata de un texto escrito desde el exilio, que es gestado antes del exilio y que además tiene como destinatarios a los protagonistas del exilio de Weimar. Se trata de un balance histórico de una época, de una extracción de conclusiones para el movimiento obrero, pero también ante todo de una guía a actuar de cara al futuro. Sin duda alguna Bloch valoró mucho su texto porque lo reeditó en 1962 en Aufbau Verlag en Berlín y en Suhrkamp en Fráncfort, incluyendo en esta reedición textos anteriores a la redacción de 1935 que en algún caso se remontan a 1929 y que se cierran con el post-scriptum de 1962.

Más objetivamente podemos decir que nos encontramos ante un gran documento histórico en el que el cronista, en el diagnóstico de su época, hace una acertada utilización de categorías sociológicas que toma prestadas de Georg Simmel y Siegfried Kracauer. Igualmente podemos decir que nos encontramos ante un buen libro de historia de la filosofía donde reciben un trato duro y acerado el psicoanálisis jungiano, la fenomenología, la ontología de Heidegger, el neokantismo, el empiriocriticismo y el socialismo vulgar. Por otra parte nos encontramos ante un magnífico libro de estética y teoría de las artes donde son denostados el formalismo de ciertas vanguardias frías como la nueva objetividad y el cubismo y la tibieza lúdicamente vacua del surrealismo. Críticas opuestas al trato generoso, implicado y empático del expresionismo alemán y sobre todo del teatro épico de Bertolt Brecht.

Particularmente el autor de este artículo ha tenido la suerte de manejar de primera mano el texto de Bloch porque se le encargó hace unos años su traducción que estará incluida en su primera edición al castellano ${ }^{2}$.

Vamos a hacer un breve repaso de algunos de los núcleos temáticos de Herencia. Para empezar resumiremos y comentaremos el Prólogo a la edición de 1935 y el Postscriptum de 1962.
Comenzaremos citando:

"Desde aquí se puede divisar una amplia panorámica. El tiempo está en decadencia y está gestando algo simultáneamente. La situación es misera o infame y el camino por el que se puede salir de aquélla es tortuoso, sin embargo, no cabe duda de que el fin no será burgués" (Bloch, 1985, 15/ 1) $)^{3}$.

El presente, aparte de misero e infame, es burgués. Sin embargo en todo presente y en este también, cómo no, se encuentra el germen para el cambio. Y el movimiento de la realidad objetiva hará que el fin no sea burgués. Quizás este planteamiento pueda ser acusado de determinista. Probablemente sea acertada esa calificación. Pero no nos equivoquemos, sólo lo es en parte. Se trata de un planteamiento determinista, pero no fatalista. El planteamiento valora al hombre, a la clase obrera, el proletario, el órgano de cumplimiento del plan de la historia. Ese determinismo no excluye ni la conciencia ni la acción, sino que la implican. Como bien señala Muguerza, la ontología materialista de Bloch pareciera contradecir su primado de la razón práctica. Precisamente lo sobresaliente en Bloch es que su hondo materialismo no ofuscó jamás el énfasis ético de su pensamiento ${ }^{4}$. De ahí que esa adscripción al devenir mismo del ser no sea un dejarse llevar sin más, se trata de una adscripción consciente, voluntaria y activa, es tributaria del Tratado Teológicopolítico de Espinosa y muestra en última instancia que Bloch, al igual que Baruch, era un pensador de origen judío. Al fin y al cabo influido por una noción lineal y no cíclica de la historia, con una apertura hacia lo mesiánico y con el componente de solidaridad humana contenida en el Talmud, "quien salva a un hombre salva a la humanidad"5. Lo que ocurre es que el Talmud también une a ese matiz de solidaridad el de exclusivismo, el de un grupo de representantes privilegiados y escogidos de cara a la salvación de la humanidad, los judíos. Allá donde el Talmud pone al judío como representante de la humanidad, el marxismo pone al proletariado. Allá donde la Torah establece proféticamente el destino del pueblo judío, los clásicos del marxismo apuntan a una profecía-objetiva basada en las condiciones materiales de producción. Sin embargo tanto Torah ${ }^{6}$ como marxismo coinciden en que el indicio de la salvación y la emancipación es la miseria del presente, el dolor, la esclavitud, la explotación, el destierro, la alienación ${ }^{7}$, etc. 
Sigamos citando fragmentos del Prólogo.

"Lo nuevo se presenta bajo una forma especialmente compleja. Aqui lo estamos considerando en sí, también en aquello que impide su llegada, Pero sobre todo lo consideramos en la ruptura involuntaria y en algunas de sus señales irisadas. Éstas, por supuesto, sólo pueden rastrearse entre las víctimas los engañados y los embriagados" (Bloch, 1985, 15/1).

Para Bloch, ateo-mesiánico, lo nuevo es divisado en la "ruptura involuntaria" y en las "señales irisadas". Aquí Bloch toma como auténtico barómetro de su época a la propia burguesía a la que alude con la "ruptura involuntaria" de su conciencia. Y por otra parte también considera un buen lugar para buscar el germen de cambio que lleva consigo su época "a las víctimas, a los engañados, a los embriagados". En esto Bloch sigue a Baudelaire en Las flores del mal y a Benjamin en la obra de los pasajes. Sin embargo, en Bloch no se acepta como inevitable y fatal el spleen moderno. No se considera el spleen punto de inicio y punto final o resultado de un camino de ida y vuelta, sino sólo muestra del malestar que debe ser suprimido y será suprimido por la emancipación del hombre.

De ahí que Bloch no se contente con mencionar a los engañados, también se refiera a los engañadores, la clase política burguesa y nacionalsocialista que alarmó a los trabajadores creando "susto" y "confusión". Éste es uno de los rasgos más distintivos de este libro en particular y de la producción general de Bloch. Mientras que el rastreo en la miseria de nuestros días del novum donde se encuentra el germen del cambio es un rastreo y por lo tanto un escrutar lo oculto, la detección de los promotores y sustentadores de la opresión es precisa, y puede ser precisa porque están bien localizados en el capital y en sus correas de transmisión. Por eso Herencia es un libro valiente. Capaz de afrontar la teoría, pero igualmente capaz de no parapetarse en ella y así eludir la muestra clara de la faz de la opresión.

Sin embargo, es muy importante ponderar que a Bloch no le basta una evocación y un contacto estrictamente estético, en cuanto desinteresado, con los embriagados, las víctimas, los engañados y mucho menos le interesa una adhesión sentimental a ellos. Bloch quiere hacer operativo el trabajo intelectual empleado en la revisión de la situación de las víctimas y en el examen de la quebrada conciencia de la burguesía de su época.
Cuando Bloch se pregunta "¿En su desmoronamiento la burguesía aporta los elementos para construir un nuevo mundo?" (Bloch, 1985, 15/1), el filósofo de Ludwigshafen ${ }^{8}$ está retomando la corrección que Lukács hizo a la teoría del reflejo de Lenin. Según Lukács no es tanto la explícita muestra de las condiciones de explotación donde se obtiene un mejor reflejo de las fuerzas sociales objetivas, sino precisamente en la resistencia a aquellas de la clase burguesa. El malestar y la decadencia de la burguesía muestran mejor lo social y el futuro cambio que el realismo socialista con su optimismo reivindicativo y la queja contra la explotación. Precisamente en el desbrozo de ese malestar o mejor dicho, de las fuerzas emancipatorias contenidas en ese malestar, se encuentra la herencia de nuestro tiempo, la herencia dialéctica de nuestro tiempo. Ya se sabe que la noción del marxismo clásico en la que se basa Lukács para formular su corrección a la teoría del reflejo es el desarrollo desigual. Es decir los diferentes tempi y ritmos de crecimiento y desarrollo de las fuerzas de producción por un lado y de las relaciones de producción por otro. Esta contradicción apunta a una tendencia histórica, el sobrepaso y el arrumbamiento de las relaciones de producción, que produce, claro está, malestar en la clase dominante. Sin embargo, señala Lukács, como ya lo hicieran Marx y Engels, que el desarrollo económico de Alemania es especial. Comparada sobre todo con Francia o Inglaterra, se trata de un país atrasado. Este desarrollo desigual en sentido estrictamente material lleva consigo una no-contemporaneidad genuina y autóctona alemana ${ }^{9}$. Para Bloch es preciso abordar esa no-contemporaneidad ${ }^{10}$.

Además en la Alemania de Weimar se asiste a una pauperización y a una proletarización crecientes de la población, producidas por dos fenómenos: las capitulaciones de Versalles y el Crack del 30. Bloch quiere convertirse en escrutador de su época y hace una crónica-balance de la República de Weimar. Llama a los años del 24 al 29 "la distracción" y a lo sucedido en la época en global "la embriaguez".

En el proceso de derrumbe económico hay dos grupos sociales especialmente perjudicados y en los que se manifiesta especialmente el malestar, los campesinos y los empleados; su malestar sirve a la reacción.

Comoquiera que el desarrollo de las fuerzas productivas es sentido por unos y otros como empobrecimiento, en ambos 
grupos se gesta un retorno al romanticismo renuente al progreso. Un romanticismo especialmente reticente a la jaula de hierro del progreso, a lo grisáceo de la autoridad legal-racional. Esta susceptibilidad les Ileva a abrazar la reacción poniéndose en manos del nacionalsocialismo.

El movimiento obrero, en lugar de caer en un mecanicismo falsamente optimista, ha de ser consciente de la fuerza que bien empleadas pueden tener las nociones románticas.

"La vida, el alma, el inconsciente, la nación, la totalidad y semejantes anti-mecanismos no serían utilizables reaccionariamente al cien por cien, si la revolución no sólo quisiera, razonablemente desenmascarar estas categorias sino también de un modo igualmente razonable, sobrepujar al antiguo poseedor de las mismas y hacerse dueña de ellas" (Bloch, 1985, 18/2).

En el momento en que Bloch vive es especialmente importante que el socialismo se dé cuenta de que no sólo es hijo de la ilustración, desmitificadora, sino también de un romanticismo capaz de reavivar el mito a favor de la revolución. Para Bloch conceptos originariamente románticos, organicistas o renuentes contra un progreso contienen también un potencial emancipatorio ${ }^{11}$. De ahí que sea urgente recoger todos esos contenidos de la reacción romántica como herencia de nuestro tiempo. Eso sí se trata de algún modo de subordinar el mito romántico, al más grande de los mitos, a la utopía concreta de la revolución como culminación del proceso ilustrado. Como muy expresivamente dice Bloch su libro "no ayuda al diablo, sino que intenta quitarle -con un enorme esfuerzo- sus armas mentirosas y sus artificios" (Bloch, 1985, 19/3). Para entender y superar los remedios que se administran al burgués depauperado en contra de la revolución verdadera, hay que estar, diabólicamente, dice Bloch, en el país del burgués o mejor dicho en su barco ${ }^{12}$.

Habiendo hecho esta revisión de las intenciones de Bloch, planteadas en su prólogo, contemplemos brevemente el Post-Scriptum a la edición de 1962. Éste fue elaborado por Bloch, una vez establecido en Tubinga, en su tercer exilio, en este caso de la República Democrática Alemana, tras la frustrante evidencia que supuso para él la construcción del muro de Berlín. En el texto el autor se lamenta de que el más grande movimiento de liberación se haya alienado de sí mismo. Esa alienación procede del elemento que le falta para la emancipación, el de la tradición del derecho natural, de la dignidad entendida como "facultas" buscada para andar en posición erguida. La ausencia de ese elemento fue el que hizo que el socialismo condujera al arquetipo del muro en vez de propiciar lo que Ilamo Engels en el Anti-Dühring salto de "la necesidad al reino de la libertad" (Bloch, 1985, 22/5). Una vez más Bloch insiste en la necesidad de aceptar y asimilar la herencia como clave para superar los errores de diagnóstico histórico.

El libro propiamente dicho comienza con unos textos aforísticos reunidos bajo el título genérico de "El polvo". Se usa aquí la escritura de un modo análogo a como lo hizo Benjamin en la obra de los pasajes y el propio Bloch en Huellas. "El polvo" es una acerada diatriba contra la pequeña burguesía. Esa clase que por estar compuesta por individuos que piensan sólo en su propio bien, sólo existe a medias. De la pequeña burguesía se rechazan su pequeñez, su mezquindad criticona, su propensión a adular al empleador. Igualmente se rechaza su denuesto de los vicios ajenos, no porque el pequeñoburgués no los tenga, sino porque no los ha aprendido. Pero en definitiva lo más significativo y lo que más deplora Bloch de la clase media es su distracción. Cómo sustituye la gran cultura por la vida distraída. Al hilo de esto cabe recordar que uno de los primeros lectores señalados de Herencia fue Hermann Hesse, quien reseñara la obra nada más publicada ${ }^{13}$. Si a Hesse le interesa Bloch y muy concretamente Herencia, es por su distancia respecto a los años veinte, los happy twenties, ésos que Bloch llamara "la distracción y que Hesse denominó la "época folletinesca".

"El polvo" es el preámbulo de la primera parte del libro Empleados y distracción, en el fondo un desarrollo de ese preámbulo. Efectivamente aquí Bloch habla de los primeros tiempos de la República de Weimar, esos que discurrieron por los "felices veinte" y supusieron la eclosión relumbrante y ficticia de la pequeña-burguesia, de su ocio barato y su distracción. Sus triviales cafés, películas y parques de atracciones le llevan a adquirir la falsa conciencia de distinguirse de un proletariado al que cada vez está más materialmente equiparado. Aquel mundo de distracción contribuyó a dividir a la clase trabajadora entre la proletarizada y la proletaria, entre la sólo resentida y la revolucionaria. 
Hay una famosa película dirigida por Sydney Pollack en 1969 llamada Danzad, danzad malditos, la cual se halla ambientada en los Estados Unidos de la Gran Depresión y discurre durante un Maratón de Baile en el que la pareja ganadora obtendrá un ansiado premio en metálico ${ }^{14}$. Esa película pareciera haberse inspirado en el texto de Bloch "Furia y ganas de reír" que data de 1929 y esté encuadrada en la Segunda Parte de Herencia. En este texto se muestra descarnadamente cómo el capital aprovecha la desesperación de los individuos y alegoriza la época como una tortura. Los bailarines son parados, desempleados pequeñoburgueses y proletarios que llenan tres cuartos de la sala haciendo pasar por deporte lo que es un martirio. Bloch advierte que más de la mitad de los presentes en la sala son votantes de los nazis.

A la distracción de los veinte, al espectáculo trivial de entonces, le sucedieron otros espectáculos, eso que Benjamin denominó la estetización de la política.

\section{Citamos de nuevo:}

"A las luces de Hollywood que apelaron únicamente a nuestros sueños, les siguieron los desfiles militares al paso de la oca, que sí se meten en la sangre... Los desempleados se vuelven carne de cañón bajo la caza salvaje y audaz de Lützow y otras autarquías en pie de guerra, la revolución se olvida bajo los tambores de guerra" (Bloch, 1985, 59/25) ${ }^{15}$.

El nazismo supo suplantar la revolución por la apariencia de la misma y transmutar la revolución por la guerra. "Manual de apariencia revolucionaria" es un texto, que aunque data de 1933 fue insertado en Herencia por Bloch en la edición de 1962. En éste se da cuenta de la manipulación nazi. La cual primero usurpó el color rojo de la bandera al proletario y después la calle, las manifestaciones y la presión propagandística que desde ellas se ejercía. A la proclamación de la República de Weimar, que acabara con la monarquía de los Hohenzollern se le llamó "Crimen de noviembre". Igualmente se acuñaron términos en sustitución de otros: "crisis" fue sustituido por "ondulación de la vida económica". Y "proletario" desapareció en beneficio de trabajador, un trabajador en sí mismo, olvidando que la inmensa mayoría de los trabajadores no lo son en sí mismos sino para otros, y en virtud de una alienación de su propio ser. De ese modo, ideológicamente, se hicieron difusas, borrosas e inadvertidas para los embriagados, las diferencias entre el explotador y el explotado, y absolutamente pasada por alto la lucha de clases. Así, apoyándose en el mito de la nación creó una imagen interclasista del trabajo. Las siglas NSDAP significan Partido Nacionalsocialista de los Trabajadores Alemanes.

\begin{abstract}
"De ahí que en el fraudulento mundo de los nazis desde los Thyssen hasta el último estibador tan sólo hay un Frente del Trabajo, y de ahi que el día de los Campesinos del Reich en Goslar no reconozca ninguna diferencia entre un gran hacendado y un pequeño campesino aparte de las insignificantes diferencias que puedan derivarse de la existente entre el área y la hectárea" (Bloch, 1985, 72/33).
\end{abstract}

Y frente a ello, el movimiento obrero autocomplaciente y determinista hizo un diagnóstico de la situación, basado en una ruinosa falta de comprensión de la herencia de la época. El autor se hace eco de un documento del KPD en 1930 en el que se confiaba en recibir la parte del león del activo de la quiebra del nazismo. El desengaño del nazismo les llegaría a los pauperizados cuando sin más su pobreza llegara a ser insoportable. Entonces una parte de éstos se haría comunista y la otra nacionalista. Sin embargo, Bloch cree que el error del diagnóstico expuesto en este documento del Partido Comunista estriba en una cuestión básica: mientras que el proletario se crió junto a las fuerzas productivas y las conoce, la conciencia semiproletaria genera una conciencia falsa cuyos contenidos se encapsulan en ideas fijas. El pequeñoburgués pauperizado se encuentra de pronto ante una tormenta de máquinas entre las que no había crecido y así se convierte o bien en un opositor irracional y tardorromántico al capitalismo o bien en un fetichista de la máquina. Un fetichista conforme no sólo con las fuerzas de producción, sino también con las relaciones de producción presentes. A este fetichista su chata capacidad de análisis le hace ver intrinsecamente ligadas unas y otras. La ideología le hace naturalizar unos vínculos que son exclusivamente históricos. En todo caso lo que está claro es que la pauperización, que lleva a un contacto súbito con la máquina, produce en el pequeñoburgués o bien la irracionalidad o bien la racionalidad mecánica. Esa última también se la achaca Bloch al marxismo vulgar. Y la alternativa que él propone es la de una racionalidad utópica consecuencia de haber asumido la herencia de su tiempo.

Y habiendo apuntado en las líneas anteriores cuál es el diagnóstico histórico de Bloch, la esencia de este libro, 
voy ahora a centrarme en algunos aspectos especificos de la herencia de su época. En primer lugar retomaré la diferencia distracción, embriaguez, y acto seguido me referiré a algunos movimientos de la supraestructura dignos de mención para Bloch por su significación histórica.

Para empezar, hay que decir que distracción y embriaguez no sólo son rótulos que le sirvieron para caracterizar dos segmentos históricos, respectivamente 1924-1929 y 1924-1933. También son términos que permiten hacer una caracterización general de la última fase del capitalismo. Precisamente la dialéctica hegeliana es la que habilita a Bloch a pasar del rótulo al término, a ir más allá del nominalismo infundiendo conceptualidad real a la distracción y la embriaguez, como aspectos de la tendencia-latencia de su tiempo.

\begin{abstract}
"La auténtica última fase del capitalismo ofrece, de un modo relativamente avanzado, el aspecto versátil de la distracción y la ambigua oscuridad de la embriaguez, en definitiva, reúne aspectos relativistas y arcaicos. Lo primero, el elemento de distracción, se halla en la desnuda aparente y extremadamente brillante objetividad; lo segundo, el elemento de embriaguez, habita en las deterioradas y ambiguas figuras de los diversos tipos de montaje" (Bloch, 1985, 214/115).
\end{abstract}

Efectivamente, dándose a sí mismo la envoltura y/o la vitola de objetividad, el capitalismo tardío pretende ser considerado activo y creativo y así se exime de reconocer que está fuertemente encadenado a la circulación de las mercancias ${ }^{16}$. Se trata de una objetividad deslumbrante que hace tomar las fuerzas de producción, el imparable avance de la técnica, por la realidad en su conjunto. Sin embargo, la sobrevaloración de la técnica propuesta desde estos parámetros abre el camino al futuro. La objetividad y el funcionalismo pueden dejar de ser distracción y convertirse en forma social válida. Está claro que desde una perspectiva marxista, el avance, el auge, el cambio de las fuerzas de producción sólo puede ser auge del capitalismo transitoriamente. Éste como conjunto de relaciones de producción obsoletas se adecuará a la nueva técnica mucho peor que las formas innovadoras y emancipatorias de vida social:

"Entonces las formas funcionales privadas de vida se convierten en formas animadas por lo social, y los pisos de bloques de alquiler de yeso blanco, en los que viven animales de carga de pequeño tamaño, cobran color y una muy diferente geometría, concretamente una auténticamente colectiva" (Bloch, 1885, 220/119).

Si la objetividad distrae con su brillante revestimiento, por su parte el montaje hace la confusión atractiva y audazmente tramada. El montaje ideológico es cometido de las nuevas corrientes de la filosofía, sin embargo, hay un montaje muy positivo, muy esclarecedor, el de la nueva novela el del teatro épico y el del expresionismo.

Y asi consecuentemente Bloch ajusta cuentas con la filosofía contemporánea, menciona con simpatía a Joyce, pondera la figura de Bertolt Brecht, y valora muy positivamente, aunque no sin crítica, al expresionismo. Todo ello partiendo de la base de que Bloch no cree estar haciendo una valoración personal de estos fenómenos, sino un balance conforme a su relevancia dialéctica.

La filosofía de su época es valorada en general de un modo negativo, pero con matices.

Bloch rechaza la sujeción de Mannheim a la facticidad de la historia, el soporte de Spengler al militarismo del segundo Reich ${ }^{17}$ o el romanticismo diluvial de Klages, una de esas filosofías fatalistas promotoras del desastre. Sin embargo, lo más destacable reside en su encaramiento del empiriocriticismo, así como en el examen de la reacción contra la filosofía de Mach que suponen la fenomenología de Husserl y la ontología existencial heideggeriana.

Bloch se hace eco de la nueva física para la que los átomos, la causalidad y el éter son en su sentido más auténtico modelos, modelos constantemente modificados y renovados, a los que, en el mejor de los casos les corresponde algo similar en el mundo. Para Mach las teorías proporcionan sólo símbolos para la práctica, no pretenden ser un reflejo de la realidad física ${ }^{18}$. En su enjuiciamiento, Bloch sigue a Lenin, señala que éste distinguía con precisión entre el relativismo físico (que libera la rigidez mecánicamente cerrada y uniforme) y su miserable filosofía, el empiriocriticismo (que no permite a ningún concepto ser aplicado directamente a la naturaleza) $)^{19}$. Lenin descubrió el aroma de clase de la teoría de la experiencia pura y libre de metafísica, pero al mismo tiempo descubre en esta filosofía reaccionaria una actitud modificada y modélica en relación con los objetos ${ }^{20}$. De ahí que "si los relativismos 
filosóficos y las intermitencias no han aportado una base sólida para el hombre nuevo al menos le han quitado su base al hombre falso" (Bloch, 1985, 295/164).

La fenomenología supone un rechazo de la explicación genético-psicológica de un hecho (Lipps), así como de toda producción trascendental que tiene su ser exclusivamente en el proceso de pensamiento (Cohen). Igualmente hay un alejamiento reactivo contra el conocimiento meramente externo del empiriocriticismo que se niega a penetrar en el fondo críptico de la experiencia ${ }^{21}$. La plenitud de una visión de la totalidad se introduce en la investigación. Frente al psicologismo, el trascendentalismo y los modelos de la filosofía adyacente a la nueva física, los fenomenólogos abogan por la realidad del mundo externo mediante la reintroducción de la intentio y la adaequatio ${ }^{22}$. Bloch aprecia este deseo de Husserl de desmarcarse de la fría abstracción cientificista. Sin embargo, comprende por otra parte que esta filosofía no quiere abandonar el idealismo burgués más que para aumentarlo con el más antiguo idealismo de tipo platónico-escolástico. $Y$ eso tiene una consecuencia indeseable desde el punto de vista político: deja a las personans insignificantes e irresueltas unas junto a otras ${ }^{23}$. Dicho de otro modo, nos hallamos ante una filosofía carente de potencial emancipatorio ${ }^{24}$, incapaz de pasar de un realismo ontológico a la constitución de un sujeto colectivo de la historia. Mucho más cuando, por el creciente relativismo, las verdades generales y las leyes esenciales de los objetos específicos se retrotraen, como ocurre con Heidegger, a la existencia y al análisis de los existenciarios ${ }^{25}$. Como señala Bloch la deriva de la fenomenología husserliana a la ontología existencial de Heidegger es análogo al tránsito del catolicismo, falsa comunidad, al protestantismo, individualidad angosta y estéril ${ }^{26}$.

Si el balance que hace Bloch de la filosofía de su tiempo es negativo, no ocurre lo mismo con ciertas manifestaciones y corrientes artísticas que llevan consigo la semilla de la liberación. Todo ello teniendo en cuenta que en la literatura lo que le interesaba a Bloch era el sueño diurno aquello que anticipa, no el nocturno que remite a un pasado ${ }^{27}$. Mientras que la filosofía de su época era una modalidad consciente del montaje que, ante la embriaguez de la objetividad, opta por el relativismo (como hace el empiriocriticismo) o por un esencialismo trasnochado (como hace la fenomenología), la contradicción se adueña del seno del arte auténtico. Para Bloch, la forma de cierto arte contemporáneo presenta "una contradicción nacida en el seno del capitalismo, compuesta de un hoy genuino, que es al mismo tiempo un hoy y un mañana concreto" (Bloch, 1985, 226, 122). En este sentido le parece admirablemente corrosiva la desquiciada narrativa de Joyce. Con el Ulises encontramos un mundo sin perspectiva, una absorción del fermento de la decadencia en primer lugar del ego (en el soliloquio interior) y luego en el contexto burgués de los sujetos. En el monólogo interior, el ego no está por testigo, y ni siquiera el cuerpo se da cuenta de que de él procede la corriente lingüística. Por otra parte, en cuanto al asunto del contexto, todo está tan desnudo, tan falto de vergüenza, tan privado de embellecimiento, que todos los naturalismos interiores se convierten en ceremonia de corte ${ }^{28}$.

Por otra parte, no hay figura por la que el autor sienta una admiración más indisimulada que por la de Bertolt Brecht Éste utiliza el montaje como una fuerza de producción como interrupción del fluir dramático, como desplazamiento didáctico de sus partes, en breve como política llevada a cabo desde la dirección escénica ${ }^{29}$. Para él Brecht era un leninista en el escenario. Su teatro es leninista en la medida en que se convierte en un estudio para cada teoría en su respectiva práctica, "su trama se convierte en una prueba previa de actitudes políticas y teorías políticas encaminadas a cambiar situaciones en el locus minoris resistentiae del escenario"30. La audiencia no pasa una noche que transcurre a su fin sin interrupciones, sino que se encuentra con una acción social interrumpida, una lógica de la situación completa, puro teatro práctico ${ }^{31}$.

El problema del expresionismo lo ve Bloch imbricado en la confluencia de arte y política. Como proponía Platón en la Politeia, toda dictadura que se siente con suficiente poder como para aspirar a ser omnímoda quiere sustentar su autoridad pedagógicamente, y estima que debe establecer un estricto control de las artes. Ya se conoce que Adolf Hitler intentó ingresar en la Escuela de Bellas Artes de Múnich, pero fue rechazado. Se dice que ese hecho fue decisivo para la deriva política que posteriormente tomara su vida. El Führer no dejó de estar interesado en las artes, ante todo en el papel educativo que éstas podian llegar a tener. En 1937 se inauguró en Múnich la Casa del Arte Alemán y al mismo tiempo la exposición itinerante "Arte degenerado". La primera era un canto al clasicismo escultórico y a la pintura de caballete, y la segunda un denuesto público, 
burlesco y peyorativo de las vanguardias históricas, especialmente de la más prolífica en Alemania, la expresionista. Nolde, Heckel, Kirchner, Barlach, Pechstein, Beckmann, Kokoschka, Kandinsky y Schmitt-Rottluff se encontraban entre los degenerados. En esta inauguración el Führer tomó la palabra: "Vosotros, prehistóricos inmoladores del arte, queréis un tipo humano bello y radiante. ¿Y qué producís? Inválidos contrahechos y cretinos, hombres que están más cerca de los animales que de los seres humanos y esto es lo que los más crueles de los diletantes se atreven a presentar como aquello que caracteriza a nuestro tiempo y le imprime su sello"32.

La exposición "Arte degenerado" fue visitada por cuatro veces más personas que la Casa del Arte Alemán. Sin embargo, también es evidente que esto no indicaba precisamente que los visitantes fueran mayoritariamente a admirar el arte que alli se exponía, sino a mofarse, a escarnecer 0 a escandalizarse cínicamente del arte que allí se pretendia humillar.

A Bloch le interesan de un modo muy secundario los juicios del Führer, le parece mucho más relevante otra indole de cuestiones. Por ejemplo la valoración de Lukács, quien la considera una expresión pequeñoburguesa, una manifestación de la superestructura capitalista. 0 cómo el juicio contra el expresionismo de los nazis fue compartido por ciertos intelectuales "esquemáticos" de Moscú ${ }^{33}$.

Bloch apreciaba el expresionismo porque encarnaba como ningún otro movimiento artístico el binomio tendencialatencia. El expresionismo según el autor

"contiene anticapitalismo subjetivamente inequivoco y objetivamente oscuro todavía. Contiene sombras arcaicas mezcladas con luces revolucionarias, caras ocultas de un mundo subterráneo no dominado, luces brillantes de un futuro, riqueza e indestructibilidad de la expresión humana" (Bloch, 1985, 258/142).

Pero, y aquí Bloch es taxativo, el expresionismo no es decadentismo inerte, spleen fatal, ni tampoco es, sirviéndose de una imagen bíblica, "realidad diluvial falsificada", tal como ocurre en los malos expresionistas, tipo Gotfried Benn, que además de mal expresionista, fue nazi. En el expresionismo "hay una integración de lo-que-ya-no-es-consciente en lo-que todavía-no-es-consciente, de lo que hace tiempo ya pasó en lo que todavía no ha pasado" (Bloch, 1985, 260/143). Se dice, recuerda Bloch, que hay expresionismo allá donde hay arte, allá donde el sentimiento no reglado tiene más peso que el entendimiento. Es pues lo subjetivamente humano constituye lo positivo de la innegable y ambigua subjetividad del expresionismo ${ }^{34}$. Esta presencia de lo subjetivamente humano como núcleo del movimiento es básica para Bloch, quien sabía que en "el expresionismo con su unidad estilística, con su antropocentrismo, se facilitaba un proceso de fundamentación antropológica de la estética, una vía para convertir el rechazo del viejo mundo en imaginación creativa del futuro" (Jiménez, 1983, 27) Desde la amplia definición de expresionismo de Bloch está claro que quien proporciona un puente para ir de esa definición genérica del expresionismo a éste valorado como un estilo son Van Gogh y Gauguin. Del primero nos dice que en él las cosas hablan por sí mismas no como un eco del hombre que resuena en ellas, es decir, la introspección y el mundo externo son puntos de partida que en primera instancia aportan sus contenidos pero luego se retraen, para que la cosa hable por sí misma ${ }^{35}$.

Pero fundamentalmente el expresionismo es un problema en el mejor de los sentidos un problema candente en cuanto irresuelto. Esto es así porque la época expresionista ha roto todas las casuales rutinas y las asociaciones convencionales del pasado: las personas que trataban con las obras de aquellos que asumían como padres "no eran herederos, sino epígonos, de ellos se podía decir lo que decia Goethe: "Weh dir, dass du ein Enkel bist" (Ay de ti que eres sólo un nieto). Los jóvenes que se están renovando a sí mismos una y otra vez no necesitan huir al pasado, sino que toman al pasado como documento" (Bloch, 1985, 263/145).

El expresionismo fue un montaje, y el montaje, como afirmaba Bloch, era embriaguez. Sin embargo, en cuanto embriaguez insatisfecha, desazonadora, fue un montaje y una embriaguez emancipatorios. Al fin y al cabo la gran enseñanza que se puede sacar en general del pensamiento de Bloch es que el hombre puede confiar en el futuro atendiendo a lo que es él y su historia ${ }^{36}$. Sin duda alguna, debido a su carácter de transitoriedad en acto, el expresionismo fue una de las piedras de toque básicas para comprender de un modo cabal la herencia de su época. 
1 Hasta el punto de que su inicial estancia en Suiza sólo pudo prolongarse hasta el 28 de agosto de 1934, las autoridades locales le denegaron una prórroga a su permanencia en Suiza: "Ihr Schreiben vom 28. August beantwortend, teilen wir Ihnen mit, dass Ihrem Ansuchen um Erstreckung der Ihnen gesetzten Ausreisefrist nicht entsprochen werden kann. Sie haben somit das Land auf den festgesetzten Termin zu verlassen. Die Ihnen ursprünglich auf Zusehen hin eingeräumte Tolerierung wurde abgebrochen, weil Sie für die einwandfreie Beobachtung der Toleranzbedingungen keine genügende Gewähr bieten. Hochachtungsvoll Eidg. Fremdenpolizei." Ernst Bloch viajó a través de Maloja y vivió durante algún tiempo en Menaggio junto al Lago de Como, y estuvo en diferentes ocasiones en Milán. No podía moverse con libertad en la Italia fascista. De octubre de 1934 al verano de 1935 Bloch permaneció en Viena y allí marchó a Paría desde donde emigró a América en 1938. cit. sg. Martin Übelfahrt en www.salecina.CH.

2 El texto irá prologado por José Jiménez con notas y traducción de Miguel Salmerón. Después de que no fraguara su edición en la Colección Neometrópolis de Alianza/Tecnos, su publicación está prevista en Taurus.

3 El segundo número de página de todas las citas textuales de la obra de Bloch que es el núcleo del artículo corresponderá al texto electrónico de mi traducción.

4 Cf. Muguerza, 1990, 387-389.

5 Talmud lerushalmi, Sanhedrin, cap. 4, 22. .

Recibido: 10 de enero de 2008 Aceptado: 23 de abril de 2009

6 Al igual que Spinoza, Bloch tomó la Biblia por una de las fuentes principales para su reflexión. "La interpre- tación de está elaborada por Bloch" está presidida por un principio metafísico a priori: el "todavía-no-ser", Ureña Pastor, 1986, 486

7 "La teología puede empezar a reflexionar sobre su tema a partir de la esperanza y en una dirección escatológica", Moltmann, 1968, 13.

8 No es ocioso llamar así a Bloch, pues él se sentía orgulloso de su ciudad natal, un espacio urbano en que la ausencia de idilio le había provisto de un genuino observatorio de la realidad social. En éste se podía distinguir un sucio y exhausto proletariado, un capital ávido de negocio y un ocio banal. Ludwigshafen, en definitiva mostraba una realidad proletaria y capitalista mixta y sin máscaras, Bloch, 1985, 208/113.

9 Bloch, 1985, 116/59.

10 Bloch, 1985, 122/62.

11 Aquí, así como en el inicio de Huellas los críticos humanistas de Bloch han encontrado un resquicio por el que criticar su noción de historia del hombre como prehistoria. Desde este punto de vista si la historia es presencia de la razón, si el hombre ha mostrado la grandeza de su humanidad en la historia, no cabe hablar de que el hombre todavía no es, cf. Jonas, 1995, 352.

12 Bloch, 1985, 20/4.

13 "En su meditado y sin embargo apasionado libro hace un balance de la Herencia de este tiempo, es decir, percute en nuestra cultura burguesa y capitalista, para investigar desde su punto de vista comunista qué partes y restos de esta cultura pueden ser importantes y sobrevivir en el futuro en la sociedad sin clases" (Hesse, 1935, en W.AA., 1975, 48).
14 They shoot horses. Don't they? (título original de la película) estaba inspirada a su vez en una novela homónima 
publicada en 1935 por Horace McCoy, a la sazón coguionista del filme.

15 El citado Lützow es un capitán general prusiano fundador del grupo paramilitar Freikorps.

16 Bloch, 1985, 215/116.

17 Precisamente, con una imagen de lo más paulina, Pérez del Corral señala que en 1918, el momento en que Spengler comienza a publicar La decadencia de Occidente aparece la primera versión de El Espiritu de la utopía. Así el "rayo de la utopía" ilumina a Bloch en la noche más grande que la historia haya nunca conocido, cf. Pérez del Corral, 1977, 10.

18 Bloch, 1985, 289/160-161.

19 Bloch, 1985, 293/163.

20 Bloch, 1985, 291-292/162.

21 "El interés de Bloch por ampliar el campo de la posibilidad por una parte y por acentuar el primado de la posibilidad por otro, le lleva a establecer un tercer estrato de posibilidad el posible cósico conforme al objeto (Sachhaft-objektgemäss Mögliche), Gómez-Heras, 1977, 84.

22 Bloch, 1985, 296/165.

23 En el marxismo de Bloch "es el hombre, con sus proyectos, esperanzas e impulsos, el agente más activo del proceso", Gimbernat, en W.AA, 1979, 45.

24 Bloch, 1985, 296/166.

25 Bloch, 1985, 303/168.

26 Bloch, 1985, 307/172.

27 Así Ueding señala que "la teoría del arte de Freud es retrospectiva" mientras que en Bloch "las grandes construcciones de la fantasía" apuntan al porvenir, cf. Ueding, 1974, 9.

28 Bloch, 1985, 243-244/133.

29 Bloch, 1985, 226/122.

30 Bloch, 1985, 247/135.

31 Bloch, 1985, 247/135.

32 Cit. sg., Bloch, 1985, 80/38.

33 Bloch, 1985, 257/141.

34 Bloch, 1985, 261/144.

35 Bloch, 1985, 262/144-145.

36 Cf. Zudeick, 1992, 310.

\section{BIBLIOGRAFÍA}

Bloch, Ernst (1985): Erbschaft dieser Zeit, Frankfurt, Suhrkamp.

\section{Literatura secundaria}

Gimbernat, José Antonio (1983): Ernst Bloch. Utopía y esperanza, Madrid, Cátedra.
Gómez-Heras, José María G. (1977): Sociedad y utopía en Ernst Bloch, Salamanca, Sígueme.

Jiménez, José (1983): La estética como utopía antropológica. Bloch y Marcuse, Madrid, Tecnos.

Jonas, Hans (1995): El principio responsabilidad, Barcelona, Herder.

Moltmann, J. (1968): Teología de la esperanza, Salamanca, Sígueme.

Muguerza, Javier (1990): Desde la perplejidad, Madrid, FCE.

Pérez del Corral, J. (1977): El marxismo cálido. Ernst Bloch, Madrid, Mañana Editorial.

Ramos Centeno, Vicente (1999): Bloch 1885-1977, Madrid, Del Orto.

Ueding, Gert (1974): "Bloch Ästhetiks des Vor-Scheins" en Bloch, Ernst, Ästhetik des Vor-scheins, Frankfurt, Suhrkamp.

Ureña Pastor, Manuel (1986): Ernst Bloch ¿Un futuro sin Dios?, Madrid, BAC.

W.AA. (1975): Ernst Blochs Wirkung. Ein Arbeitsbuch zum 90. Geburtstag, Frankfurt, Suhrkamp.

W.AA. (1979): En favor de Bloch, Madrid, Taurus.

Zudeick, Peter (1992): Ernst Bloch. Vida y obra, Valencia, Alfons el Magnànim. 